\title{
A LONGITUDINAL STUDY OF A NEUROPSYCHOLOGICAL REHABILITATION PROGRAM IN ALZHEIMER'S DISEASE
}

\author{
Jacqueline Abrisqueta-Gomez ${ }^{1,2}$, Fabiola Canali3, Vera L.D. Vieira ${ }^{3}$, \\ Ana Cristina P. Aguiar, Carmen S.C. Ponce, ${ }^{4}$ Sonia M. Brucki, Orlando F.A. Bueno ${ }^{6}$
}

\begin{abstract}
Our aim was to study the duration of benefits derived from a neuropsychological rehabilitation program (NRP) for dementia patients. Method: The participants in this study were three patients diagnosed as probable Alzheimer's disease in the initial-to-moderate phase; the three were taking anticholinesterases. They were submitted to a neuropsychological evaluation (NE) before the NRP and then revaluated after 12 and 24 months of treatment. The aim of our intervention was to do practical work with implicit and explicit residual memory by training them in everyday life activities, and using compensatory strategies and their intact cognitive abilities. Results: Analysis of quantitative NE data (descriptive measures) after the first year of NRP showed cognitive improvement, functional stabilization and fewer behavioral problems. However, this improvement did not continue in the second year, and the disease maintained its characteristic progression.
\end{abstract}

KEY WORDS: neuropsychological rehabilitation, cognition, neuropsychology, Alzheimer's disease, dementia, aging, memory.

\section{Estudo longitudinal de um programa de reabilitação neuropsicológica dirigido a pacientes com doença de Alzheimer}

\begin{abstract}
RESUMO - Objetivo: Estudar a duração do beneficio de um programa de reabilitação neuropsicológica (PRN) dirigido a pacientes demenciados. Método: Participaram deste estudo, três pacientes com diagnóstico de provável doença de Alzheimer em fase inicial a moderada. Todos faziam uso de anti-colinesterásicos e passaram por uma avaliação neuropsicológica (AN) antes de começar o PRN e reavaliação após 12 e 24 meses do tratamento. $\mathrm{O}$ alvo de nossa intervenção foi trabalhar de forma prática a memória explicita residual e implícita, através do treino das atividades da vida diária, uso de estratégias compensatórias e habilidades cognitivas ainda preservadas. Resultados: A análise dos dados quantitativos (medidas descritivas) da AN mostrou, que após o primeiro ano do PRN houve uma melhora cognitiva, estabilização funcional e redução dos problemas comportamentais nos pacientes. No entanto, observamos que essa melhora não se estendeu para o segundo ano, mostrando a doença sua característica progressiva.
\end{abstract}

PALAVRAS-CHAVE: reabilitação neuropsicológica, cognição, neuropsicologia, Alzheimer, demência, idosos, memória.

Although cognitive rehabilitation for dementia processes in the elderly is not included in obligatory treatment, it does bring considerable benefits in delaying the progression of degenerative diseases. Recent studies of demented patients in the initialto-moderate phases have shown that medicationbased treatment together with guided cognitive rehabilitation work may assist stabilization, or even lead to a slight improvement in cognitive and functional deficits ${ }^{1-2}$ (for a review see De Vreese ${ }^{3}$ ).

However, how long the disease can be delayed is still very uncertain, since most of the research to date has focused on periods of seven months at most. Proper evaluation of cognitive and functional decline in the patients involved in these programs requires longer-term studies to find the limits of our inter-

\footnotetext{
Departamento de Psicobiologia - Centro Paulista de Neuropsicologia (CPN) - Serviço de Atendimento e Reabilitação ao Idoso (SARI). Universidade Federal de São Paulo/Escola Paulista de Medicina, São Paulo SP, Brasil (UNIFESP/EPM): ${ }^{1}$ Neuropsicóloga, Doutora em Ciências pela UNIFESP; ${ }^{2}$ Coordenadora clinica do SARI; ${ }^{3}$ Psicóloga do SARI; ${ }^{4}$ Psicóloga colaboradora do SARI; ${ }^{5}$ Doutora em Neurologia pela UNIFESP, neurologista do CPN; ${ }^{6}$ Professor Adjunto do Departamento de Psicobiologia da UNIFESP, Coordenador Geral do CPN. Apoio financeiro: Associação Fundo de Incentivo à Psicofarmacologia (AFIP).
}

Received 19 December 2003, received in final form 22 March 2004. Accepted 7 May 2004.

Dra. Jacqueline Abrisqueta-Gomez - Psychobiology Departament UNIFESP - Rua Botucatu 852/1a andar - 04023-062 São Paulo SP Brasil. E-mail: jacky@psicobio.epm.br 
vention and help family members care for patients in the future.

On this basis, the Serviço de Assistência e Reabilitação do Idoso (SARI, an organization maintained by Associação Fundo de Incentivo à Psicofarmacologia - AFIP) has carried out experimental work in neuropsychological rehabilitation of demented patients for two consecutive years with the aim of discovering how long the benefits thus obtained will last.

\section{METHOD}

The subjects in this study were three patients aged 64 - 71, 2 male and 1 female, with schooling ranging from 4 to 15 years, all married and living with their families. Two were diagnosed by our facility as probable Alzheimer's Disease (AD) patients, and the third had already been diagnosed previously. All three patients met the criteria set by the National Institute of Neurological Communicative Disorders and Stroke - Alzheimer's Disease and Related Disorders Association 4 . None presented a clinical history of neurological, systemic or cerebral diseases that may cause dementia. All were in the initial-to-moderate phase of the disease as classified on the Clinical Dementia Rating (CDR) 5 and Mini-Mental State Examination $(\mathrm{MMSE})^{6}$. All patients and their relatives gave written informed consent to participate in this study, which was approved by the local ethics committee.

Patients were on medication (anticholinesterases) and were submitted to full neurological and neuropsychological evaluation at the start of the program in order to determine baseline parameters. Two further evaluations were conducted at 12 months and 24 months after base date.

Initial neuropsychological evaluation took place over a one-month period and all three patients were submitted to 4 sessions lasting 1 hour or more. Two sessions were held with members of their families to determine values on functional and behavioral scales.

The neuropsychological evaluation battery consisted of tests appraising cognitive damage and patients' functional impairments. Initially we applied the abbreviated neuropsychological battery NEUROPSI ${ }^{7}$, in order to quickly assess damage to cognitive functions (maximum application time 25 minutes) through the following subtests: temporal and spatial orientation, attention and concentration, language (including a semantic verbal fluency task (animals) and a phonological fluency task (words beginning with the letter F), conceptual and motor executive functions, visual (copy and delayed free recall of Rey's semi-complex figure) and verbal (memorizing 6 words) memory encompassing delayed free recall, cued recall and recognition.

We evaluated memory loss more extensively through sub-tests derived from the Wechsler Memory Scale WMS ${ }^{8}$, which included tasks to evaluate logical memory (narrative of stories - verbal contents), visual reproduction (geometric drawings - visual memory) and associated pairs (verbal learning task), all tasks with immediate and delayed retrieval. We also applied sub-tests for information, mental control (mental arithmetic task) and forward and backward digit span. This battery was complemented with other quick application tests such as Trail Making ( $A$ and $B$ ) to evaluate attention and cognitive flexibility and the Colored Raven Progressive Matrices test of intelligence through visual stimuli. Patients' deficits or incapacities arising from memory loss were evaluated using the Rivermead Behavioral Memory Test ${ }^{9}$, which include tasks using certain aspects of memory in everyday situations.

Functional evaluation was made by the Basic Daily Living Activities Scale (BADL) ${ }^{10}$, consisting of 17 categories including tasks such as using the telephone, personal hygiene, locomotion, etc. There are 3 possible scores for each category in accordance with the level of the patient's dependence, the maximum being 48 points with lower scores on this scale meaning less dependence. The Revised Memory and Behavior Problems checklist (RMBP) was also applied ${ }^{11}$. This scale has two parts: one evaluates the frequency of the patient's behavioral problems and the other caregivers' responses to problems. High scores mean greater frequency of behavioral problems and caregivers' negative responses to the problems.

Additionally, we evaluated patients' thought processes in order to elucidate their suitability for group tasks. In this type of evaluation the task was to group 30 figures in five different semantic categories (six figures per category). From the types of grouping made by the patient, it is possible to observe whether thought was functional (grouping objects by use), disorganized (no apparent relationship in grouping procedure) or more refined (grouping according to semantic categories). These patients made groupings on a mixed basis, grouping by semantic and functional categories combined, which suggests a promising basis for rehabilitation work based on this preserved ability.

\section{Neuropsychological rehabilitation program (NRP)}

NRP interventions were planned on the basis of cognitive loss, functional restrictions and behavioral problems depending on the profile obtained from neuropsychological evaluations; this was an essential part of the design of our rehabilitation program. The aim of our intervention was to do practical and dynamic work with the patient's semantic and affective memory together with training in daily living activities and their intact cognitive skills. For this purpose, we employed techniques such as reality guidance orientation, reminiscence, and expanding rehearsal with (to facilitate retention of information), and we encouraged the use of external supports. Some of these proposals are derived from cognitive and behavioral psychology research.

Sessions with the patients took place twice weekly, one in-group and the other individual. The group session lasted 1.5 hour at most, and individual meetings 1 
hour. Individual meetings with family members took place fortnightly to talk about the patient's development and restructuring of daily living activities, as well as show them the stimuli required at home during the month. Monthly group meetings were held to provide information on the nature of the disease and how it related to each patient's daily life. Note that family members were asked to motivate patients that still had cognitive potential to take up an activity or hobby they had practiced skillfully in the past.

Table 1. Performance in the NEUROPSI and Screening tests (means and standard deviations). before and after NRP

\begin{tabular}{|c|c|c|c|c|c|}
\hline NEUROPSI & $\begin{array}{c}\text { T1 } \\
\text { Baseline } \\
\text { assessment }\end{array}$ & $\begin{array}{c}\text { T2 } \\
\text { After } 12 \\
\text { months }\end{array}$ & $\begin{array}{c}\text { T3 } \\
\text { After } 24 \\
\text { months }\end{array}$ & $\Delta 1$ & $\Delta 2$ \\
\hline Total score & $79.2(8.4)$ & $87(3.7)$ & $68.8(17.0)$ & +8 & -10 \\
\hline \multicolumn{6}{|l|}{ Orientation } \\
\hline Time & $1.3(0.5)$ & $3(0)$ & $1.3(0.5)$ & +2 & $\leftrightarrow$ \\
\hline Space & $2(0)$ & $2(0)$ & $1.3(0.9)$ & $\leftrightarrow$ & -1 \\
\hline Person & $0.7(0.5)$ & $1(0)$ & $0.7(0.5)$ & $\leftrightarrow$ & $\leftrightarrow$ \\
\hline \multicolumn{6}{|l|}{ Attention } \\
\hline Visual detection & $12.3(1.7)$ & $8(1.4)$ & $8(2.4)$ & -4 & -4 \\
\hline Twenty minus three & $4.3(0.5)$ & $4.3(0.9)$ & $3.3(2.4)$ & $\leftrightarrow$ & -1 \\
\hline \multicolumn{6}{|l|}{ Memory encoding } \\
\hline Words (immediate) & $4.7(0.9)$ & $5(0.8)$ & $4(1.4)$ & $\leftrightarrow$ & $\leftrightarrow$ \\
\hline Copy figure (SEMI) & $10.7(1.0)$ & $12(0)$ & $11.2(1.2)$ & +2 & $\leftrightarrow$ \\
\hline \multicolumn{6}{|l|}{ Delayed recall } \\
\hline Words (free recall) & 0 & $0.3(0.5)$ & 0 & $\leftrightarrow$ & $\leftrightarrow$ \\
\hline Cueing & $1.3(1.2)$ & $1(0.8)$ & 0 & $\leftrightarrow$ & -1 \\
\hline Recognition & $4(2.2)$ & $3.7(2.6)$ & $2(1.6)$ & $\leftrightarrow$ & -2 \\
\hline Semi complex figure & $1.5(1.8)$ & $3.3(1.7)$ & $2.3(0.5)$ & +2 & +1 \\
\hline \multicolumn{6}{|l|}{ Language } \\
\hline VF (animals) & $14.3(2.6)$ & $11.3(3.1)$ & $9.7(2.6)$ & -3 & -5 \\
\hline VF (letter F ) & $9(2.9)$ & $13.7(9.2)$ & $7.7(5.6)$ & +4 & -1 \\
\hline Comprehension & $4.3(1.7)$ & $5.3(0.9)$ & $5(0.8)$ & +1 & $\leftrightarrow$ \\
\hline Naming & $7.3(0.9)$ & $8(0)$ & $7.3(0.5)$ & $\leftrightarrow$ & $\leftrightarrow$ \\
\hline Repetition & $3.7(0.5)$ & $4(0)$ & $4(0)$ & $\leftrightarrow$ & $\leftrightarrow$ \\
\hline Reading & $1(0.8)$ & $2(0.8)$ & $1(0.8)$ & +1 & $\leftrightarrow$ \\
\hline Writing & $0.7(0.5)$ & $1(0)$ & $0.7(0.5)$ & $\leftrightarrow$ & $\leftrightarrow$ \\
\hline Copy of sentence & $1(0)$ & $1(0)$ & $1(0)$ & $\leftrightarrow$ & $\leftrightarrow$ \\
\hline \multicolumn{6}{|l|}{ Conceptual functions } \\
\hline Similarities & $3.7(2.1)$ & $5(0.8)$ & $4.3(0.9)$ & +1 & $\leftrightarrow$ \\
\hline Calculation abilities & $2.3(0.5)$ & $2.3(0.5)$ & $1.7(1.2)$ & $\leftrightarrow$ & $\leftrightarrow$ \\
\hline Sequences & $0(0)$ & $0.3(0.5)$ & $0.7(0.5)$ & $\leftrightarrow$ & $\leftrightarrow$ \\
\hline \multicolumn{6}{|l|}{ Motor functions } \\
\hline Right-hand position & $0.7(0.5)$ & $1.3(0.9)$ & $0.7(0.9)$ & $\leftrightarrow$ & $\leftrightarrow$ \\
\hline Left-hand position & $1.3(0.5)$ & $1.7(0.5)$ & $0.3(0.5)$ & $\leftrightarrow$ & -1 \\
\hline Alternating movements & $1.3(0.5)$ & $1.7(0.5)$ & $1.3(0.9)$ & $\leftrightarrow$ & $\leftrightarrow$ \\
\hline Opposite reactions & $1.7(0.5)$ & $2(0)$ & $0.7(0.9)$ & $\leftrightarrow$ & -1 \\
\hline \multicolumn{6}{|l|}{ Testes screening } \\
\hline MMSE & $23.7(3.3)$ & $24.3(5.2)$ & $23.7(1.9)$ & $\leftrightarrow$ & $\leftrightarrow$ \\
\hline Trail making A (sec) & $73(38.0)$ & $66(34.3)$ & $132.3(93.3)$ & +7 & -59 \\
\hline Trail making B (sec) & $323(183.2)$ & $289.3(210)$ & $218.5(35.5)^{*}$ & +34 & $+104 *$ \\
\hline Raven scale & $26.7(2.6)$ & $28(3.3)$ & $30(4.5)$ & +1 & +3 \\
\hline
\end{tabular}

$T 1$, Baseline assessment (1 ${ }^{\text {st }}$ evaluation); $T 2,2^{\text {nd }}$ evaluation; $T 3,3^{\text {rd }}$ evaluation; $\Delta 1$, difference between evaluations T1 and T2; $\Delta 2$, difference between evaluations T1 and T3; (SEMI), semicomplex. *Results of means and standard deviations of 2 patients. 
Table 2. Memory and learning test (means and standard deviations) before and after NRP.

\begin{tabular}{lccccc}
\hline Test & $\begin{array}{c}\text { T1 } \\
\text { Baseline } \\
\text { assessment }\end{array}$ & $\begin{array}{c}\text { After 12 } \\
\text { months }\end{array}$ & $\begin{array}{c}\text { T3 } \\
\text { After 24 } \\
\text { months }\end{array}$ & $\Delta 1$ & $\Delta 2$ \\
\hline Verbal memory logical (IM) & $9.3(4.5)$ & $10.3(7.6)$ & $6.3(6.9)$ & +1 & -3 \\
Verbal memory logical (DE) & 0 & $0.7(0.9)$ & 0 & $\leftrightarrow$ & $\leftrightarrow$ \\
Visual reproduction (IM) & $22(6.4)$ & $25.7(9.0)$ & $17.7(12.5)$ & +3 & -4 \\
Visual reproduction (DE) & $1.7(1.2)$ & $1.0(1.0)$ & $2.5(2.5)$ & $\leftrightarrow$ & $\leftrightarrow$ \\
Information & $4.7(0.5)$ & $4.7(0.5)$ & $3.3(0.9)$ & $\leftrightarrow$ & -1 \\
Forward digits span & $3.3(2.4)$ & $3.7(2.6)$ & $2.7(2.1)$ & $\leftrightarrow$ & $\leftrightarrow$ \\
Backward digits span & $3.3(0.5)$ & $3.7(0.5)$ & $2.0(1.4)$ & $\leftrightarrow$ & -1 \\
PAL I time & $4.7(0.9)$ & $5.0(0.8)$ & $2.3(1.7)$ & $\leftrightarrow$ & -2 \\
PAL II time & $4.3(0.5)$ & $5.3(0.9)$ & $3.3(2.5)$ & +1 & -1 \\
PAL III time & $4.7(1.2)$ & $6.0(0.8)$ & $4.0(2.8)$ & +1 & $\leftrightarrow$ \\
PAL (DE) & $3.3(0.9)$ & $4.7(0.9)$ & $3.3(2.5)$ & +1 & $\leftrightarrow$ \\
Rivermead & $3.3(2.6)$ & $4.7(3.2)$ & $4.3(3.1)$ & +1 & +1 \\
\hline
\end{tabular}

$T 1$, Baseline assessment (1 $1^{\text {st }}$ evaluation); $T 2,2^{\text {nd }}$ evaluation; $T 3,3^{\text {rd }}$ evaluation; $\Delta 1$, difference between evaluations $\mathrm{T} 1$ and $\mathrm{T} 2 ; \Delta 2$, difference between evaluations $\mathrm{T} 1$ and $\mathrm{T} 3$; (IM) immediate; (DE) delayed (PAL) paired associated learning.

\section{Characteristics of the NRP sessions}

Each NRP session followed a specific routine and always encouraged errorless learning within the particular context of each meeting. In the initial group sessions, patients were trained to remember names of other members of the group and those of therapists using the expanding rehearsal and vanishing cues techniques. All participants managed to learn all the names after three months. Temporal orientation was stimulated by introducing and training in use of calendar and diary. At each individual session, performance was evaluated by completing a form with the following items: year, month, day of the week and day of the month; then they were asked the same questions related to the previous and subsequent day of the week. After this they were asked to describe the weather as sunny, or rainy, etc. The session continued with a discussion of the events of the month (vacations or festive occasions) and current affairs. Autobiographical memory was exercised in a guided manner through oral narrative and writing relevant events from their daily lives (birth of a new member of the family, wedding anniversary, etc). At every individual session the patient was encouraged to fill out a form that included name, address and other personal data. Both past memories (reminiscence) and cognitive exercises (attention, language, memory and others) were elaborated depending on the events related to each session and specific theme. For example, the patient was encouraged to make or write a card to be given on days such as Mothers' Day, or a birthday of some member of the group.
Daily living activities were motivated through training in answering the telephone, asking basic questions (who called, for what reason) and always noting the date when writing down messages. We also used supermarket aids for exercises in which the patient pretended to be shopping and had to reckon the bill.

\section{RESULTS}

Quantitative data were analyzed to derive descriptive measures (means and standard deviations) for neuropsychological and cognitive test scores and functional and behavioral scales. Differences $(\Delta s)$ between initial score (baseline) and first and second evaluations (after NRP) were categorized as improvement (+) or deterioration (-).

Tables 1 and 2 show that after the first year of NRP, patients had quite an exciting cognitive improvement, as seen in the results of the abbreviated NEUROPSI battery and several other memory test scores, which remained stable or showed slight improvement. There were fewer memory and behavioral problems according to the RMBP checklist (Fig 2) and there was functional stabilization on the daily living activities scale (Fig 3). However, this improvement did not continue in the second year of rehabilitation and the disease manifested its progressive and degenerative character. 


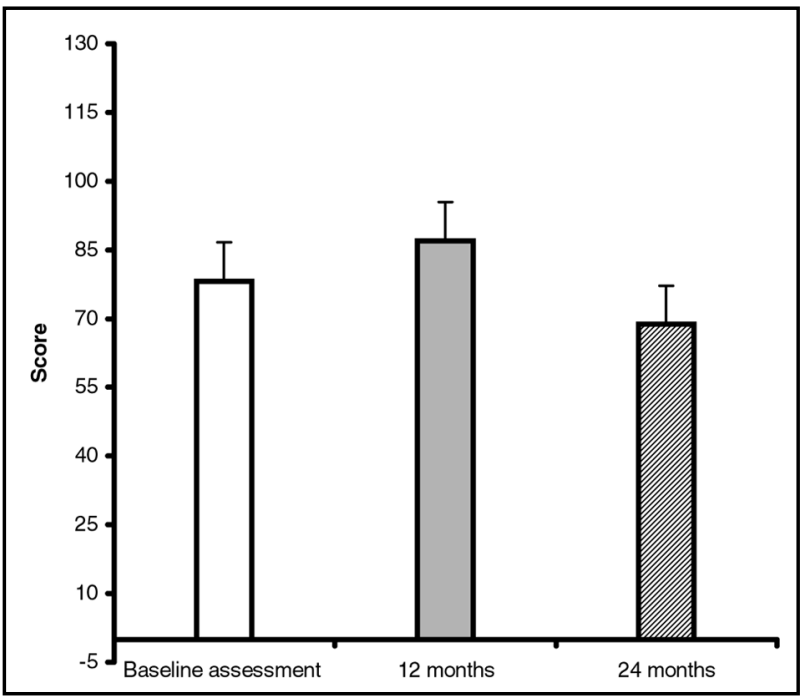

Fig 1. Result of total Neuropsi score.

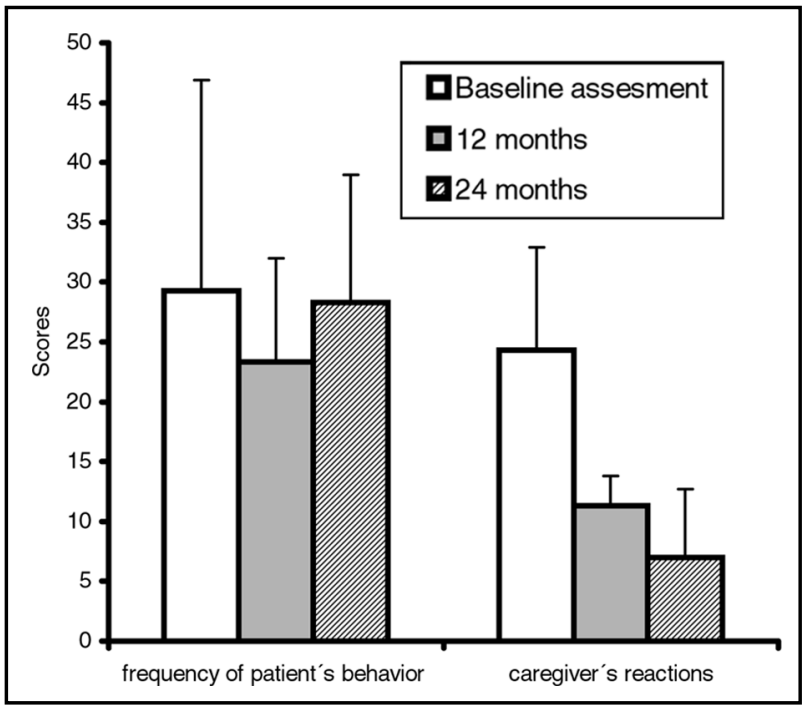

Fig 2. Results in the Revised Memory and Behavior Problems Checklist (RMBPC).

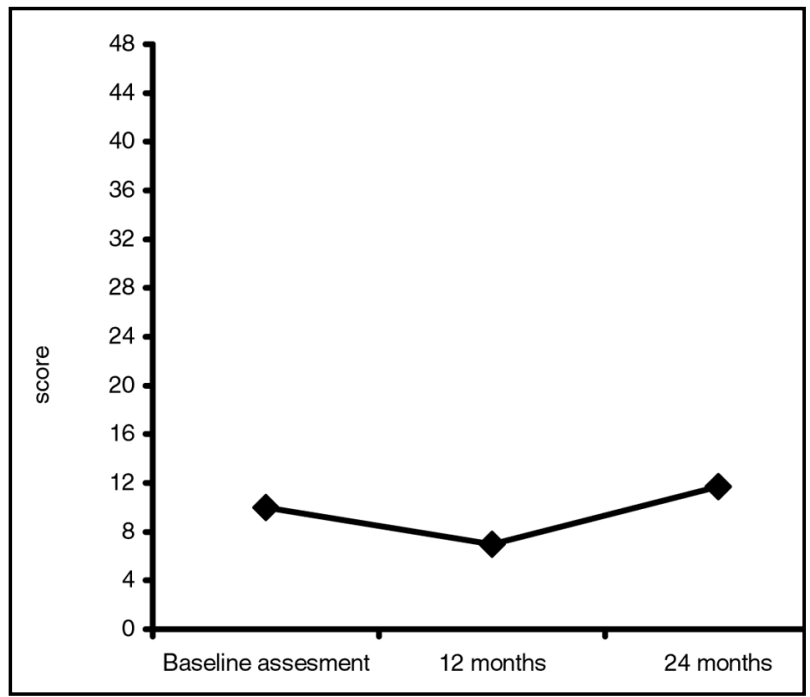

Fig 3. Results in the Basic Daily Living Activities Scale (BADL).
Subjects scored lower overall on the abbreviated NEUROPSI battery in the second year of NRP (Fig1 and Table1). Nonetheless, in certain subtests and in the MMSE they did remain stable in comparison with the baseline (Table 1). A slight improvement compared to the baseline was observed also on the Rivermead memory tests (Table 2).

Analysis of behavioral evaluation revealed higher scores on the RMBP scale in the second year, but the score increase of the second year was less than scores obtained prior the NRP. However, it is important to note that caregivers' responses to patients' behavioral problems scored lower. In spite of the increasing scores on the BADL scale after 24 months, the scores at this evaluation are not considered to reflect a high level of functional dependence (the cutoff point is 05 maximum score is 48 points) (Fig 3).

\section{DISCUSSION}

A comparative analysis of the first and the second year of rehabilitation shows that therapeutic work combining medication treatment and neuropsychological rehabilitation in dementia has proved to be effective in delaying cognitive and functional decline in these patients, and our results for the first year of intervention match those described in the literature ${ }^{12-16}$. There was an improvement in cognitive and functional performance of the patients after one year of rehabilitation, with diminished behavioral problems. However, these changes were uneven and more pronounced in certain patients than in others. This is surely due to a conjunction of factors such as the heterogeneity of the pathology itself, and differences in onset age and patients' schooling levels among others.

One of the greatest difficulties in the beginning of the treatment was the resistance from patients not wishing to take part in a NRP. This was due to a low level of awareness or perception of their illness (a frequent characteristic in AD patients), which requires time to establish a good patient-staff rapport. Therefore, it is important to understand that, to be successful, the intervention should be prolonged, lasting months with regular sessions.

We believe that the visible improvement in performance in the first year is due to NRP design that gives priority to the use of residual explicit memory, which still exists in patients in initial phases of $A D$, emphasizing autobiographical memory (through a continuous presentation of time, place and person-related information) and reality orientation, and employing reminiscence therapy (where the 
goals are to maintain or restore temporal and spatial orientation), an approach previously successfully conducted with AD patients by Spector ${ }^{17}$ and Boylin ${ }^{18}$. We would also mention the importance of the implicit learning techniques used to memorize group members' names, which were used successfully with AD patients by Camp ${ }^{19}$ and Camp and Foss $^{20}$. The use of external support (such as a diary) was more difficult to train since this training takes a long time and most patients dropped it in the second year of NRP, due to lack of support in the family environment.

We also noticed that although there was less caregiver's response to patients' behavioral problems, there was a certain difficulty in accepting the progression of the disease. This kind of response is associated with stress commonly induced by degenerative diseases in the family, together with false expectations of a "cure" when a patient is treated, in spite of explanations at all family meetings that the goal of the program was not an actual improvement but instead stabilizing the disease for a longer period.

In conclusions, NRPs are effective as long-term treatment as they lead to symptomatic benefits of a cognitive, behavioral and functional nature during the evolution of the disease, which are not evidenced in clinical studies with anticholinesterases only, even at higher doses. However, certain methodological aspects should be examined in future research with larger samples in order to obtain more reliable results and determine variables that lead to some patients benefiting more than others. In addition, the involvement of the family in NRPs are an important source for collecting information on the patients (e.g. previous lifestyle factors), that may guide selection of the appropriate treatment protocol and to help maintaining gains after systematic professional contact has ceased. For this reason, the general frame of intervention should take into consideration the caregiver's expectancies in order to guide him/her in the most effective way towards a conjoint effort with the therapists. The results obtained have matched findings already described in the literature, especially in the first year of intervention, and this may be a promising approach for improving quality of life in these patients and delaying the degenerative process, as long as we can develop intervention protocols that are standardized, replicable, consistent, valid and particularly effective for our patients' specific needs.

\section{REFERENCES}

1. Abrisqueta-Gomez J, Brucki SMD, Canali F, et al. Neuropsychological rehabilitation program in cognitive impairment and dementia. In Battistin L, Dam M, Tonin P (eds). Proceedings of the 3rd World Congress Neurological Rehabilitation, Venice: Monduzzi Editore, 2002:399-407.

2. Bottino CM, Carvalho IA, Alvarez AM, et al. Cognitive rehabilitation in Alzheimer's disease patients: multidisciplinary team report. Arq Neuropsiquiatr 2002;60:70-79

3. De Vreese LP, Neri M, Fioravanti M, Belloi L, Zanetti O. Memory rehabilitation in Alzheimer's disease: a review progress. Int J Geriatr Psychiatry 2001;16:794-809.

4. Mckhann G, Drachman D, Folstein M, Katzman R, Price D, Stadlan EM. Clinical diagnosis of alzheimer's disease: report of the NINCDS-ADRDA Work Group under the auspice of Department Of Health and Human Services Task Force on Alzheimer's Disease. Neurology 1984;34:939-944.

5. Hughes CP, Berg L, Danzinger WL. A new clinical scale for the stating of dementia. Br J Psychiatry 1982;140:566-572.

6. Bertolucci PHF, Brucki SMD, Campacci SR, Juliano YO. O mini-exame do estado mental em uma população geral: impacto da escolaridade. Arq Neuropsiquiatr 1994;52:1-7.

7. Ostrosky-Solis F, Ardila A, Roselli M. NEUROPSI: a brief neuropsychological test battery in Spanish with norms by age and educational level. JINS 1999;5:413-433.

8. Wechsler D. Wechsler memory scale-revised manual. San Antonio: Psychological Corporation, 1987.

9. Wilson BA, Baddeley AD, Cockburn JM. The Rivermead Behavioural Memory Test . 2 .Ed. Tradutores: Oliveira RM, Schmidt SL. Suffolk: Thames Valley Test Company, 1991.

10. Katz S, Downs TD, Cash HR, Grotz RC. Progress in the development of the index of ADL. Gerontologist 1970;1:20-30.

11. Teri L, Truax P, Longston R, Uomoto J, Zarit S, Vitaliano PP. Assessment of behavioral problems in dementia: the revised memory and behavior problems check list. Psychol Aging 1992;7:622-631.

12. Zanetti O, Binetti G, Magni E, Rozzini L, Bianchetti A, Trabucchi M. Procedural memory stimulation in Alzheimer's disease: impact of a training programme. Acta Neurol Scand 1997;95:152-157

13. Ermini-Funfschilling D, Hendriksen CH, Meier D, Regard M, Stahelin HB. Cognitive training for mildly demented out patients: effects on mood and cognitive functions. In Vellas BJ, Fitten LJ. (eds). Research and practice in Alzheimer's disease. Paris: Serdi Publisher, 1998:380-390.

14. De Vreese LP, Neri M. Ecological impact of combined cognitive training programs and drug treatment in Alzheimer's disease. Int Psychogeriatr 1999;11(Suppl):S187

15. Paciaroni L, Civerchia P, Castellani S, Fioravanti P, Rossi T, Scarpino O. Memory training for patients with mild Alzheimer's disease: effects on cognitive performances and mood. Neurobiol Aging 1998; 19:101(A424)

16. Davis RN, Massman PJ, Doody RS. Cognitive intervention in Alzheimer's disease: a randomized placebo-controlled study. Alzheimer Dis Assoc Disord 2001;15:1-9.

17. Spector A, Orrell M, Davies S, Woods B. Reality orientation for dementia - Cochrane review. Oxford: The Cochrane Library, 2000.

18. Boylin W, Gordon S, Nehrke M. Reminiscence and ego integrity in institutionalized elderly. Gerontologist 1976;16:118-124.

19. Camp CJ. Facilitation of new learning in Alzheimer's disease. In Gilmore C, Whitehouse PJ, Wykle ML (eds). Memory aging and dementia: theory, assessment and treatment. New York: Springer, 1989:212-225.

20. Camp CJ, Foss JW. Designing ecologically valid intervention for persons with, dementia. In Payne DG, Conrad FG (eds). Intersections in basic and applied memory research. New York : Springer, 1997:311-315. 